\title{
LA VEGETACIÓN PANTANOSA DE ITE
}

Rosario Zegarra Zegarra ${ }^{4}$

\section{INTRODUCCIÓN}

Las playas delabahía de lte son franjas angostas, conformadas mayormente por guijarros y arena, que se extienden desde la base de los acantilados, bordeando la bahía, hasta la iínea de alta marea. La formación de una larga y angosta franja pantanosa cubierta por vegetación natural, contigua a la base delos acantilados, fue originada por las filtraciones de agua de regadío provenientes de la irrigación de las pampas de Ite-Norte. A partir de 1960, año en que se inicióla deposición de relaves provenientes de la mina de Toquepala en la bahía de Ite, gran parte de la playa de guijarros quedó cubierta por arenas de relave, y el área de playa comenzó a crecer paulatinamente desde la berma litoral hacia el mar.

Simultáneamente al crecimiento de la playa, aumentó elárea devegetación natural pantanosa(bofedal), tanto en Playa Inglesa como en Playa Ite, debido a la acumulación progresiva del agua en el pantano y la invasión de la napa freática en el subsuelo arenoso de la playa.Un excedente considerable del agua proveniente de filtraciones de la irrigación Ite-Norte, discurre sobre la superficie de la playa en forma de pequeños riachuelos que llegan al mar.

La vegetación natural pantanosa y la de las arenas circundantes, sirven actualmente de forraje al ganado vacuno, caprino y ovino -propiedad de los agricultores de lte-, que pastan en ellos (en la actualidad existe una población ganadera de 1000 a 2000 cabezas de ganado caprino y ovino). La comunidad vegetal es densa, formando un tapiz verde durante todo el año y emergiendo del agua estancada. Las especies se encuentran arraigadas en el lodo.

\section{MATERIALES Y MÉTODOS}

Se ha utilizado el método de observación directa, colección fresca y de herbario. Una vez preparado el material en estudio, se procedió a la identificación, recurriendo a claves botánicas y al estudio morfológico por comparación (Braun Blanquet 1964, Gola et al 1965,
Zegarra 1993, 1994).

\section{TAXONOMÍA Y DESCRIPCIÓN BOTÁNICA DE LAS ESPECIES}

Sedaa conocer laubicación taxonómica de cada una de las especies coleccionadas.

\section{A.- CLASE MONOCOTYLEDONEAE FAMILIA : GRAMINEAE (Poaceae) \\ 1. : Distichlis spicata \\ (L.) Greene. "Grama salada»}

Planta perenne rizomatosa,dioica. Cañas floríferas de $10-40 \mathrm{~cm}$ de altura. Hojas conspicuamente dísticas, involutas de $4-5 \mathrm{~cm}$ de largo. Panojas densas y cortas de 1,5-2 cm. de longitud. Espiguillas de 5-9 flores. Glumas desiguales, anchas, agudas, carenadas, de 3-7 nervadas. Cariópside oval, comprimido lateralmente, glabro de 2,5 - $3 \mathrm{~mm}$ de longitud.

Especie americana típica de suelo salobre. Propagación por semillas y rizomas, (Fig 1).

2. Cynodon dactylon (L.) Pers. "Grama dulce, gramilla, pasto Bermuda, pata de perdiz".

Planta rizomatosa y estolonífera. Cañas floríferas de $10-20 \mathrm{~cm}$ de altura, decumbentes o erguidas. Hojas angostas y cortas de 1,5-2 cm de largo por 1,5 - $2 \mathrm{~mm}$ de ancho. Espigas unilaterales en número de $4-8$ que parten de un mismo punto del tallo; de color violáceo. Espiguillas comprimidas, con 1-2 flores, en dos hileras a lo largo de uno de los lados del raquis continuo, sésiles, pequeñas de $2 \mathrm{~mm}$ de longitud. Glumas desiguales, separadas, agudas, carenadas, uninervadas, más pequeñas que la flor. Flores con tres estambres y estigmas terminales libres. Fruto en cariópside, oblongo, comprimido lateralmente, terminando casi en punta, de color castaño rojizo de 1,1 a $1,5 \mathrm{~mm}$ de longitud. Se propaga por semillas y vía vegetativa por rizomas y estolones. Especie cosmopolita.

En la comunidad estudiada, los individuos de ésta especie adoptan un porte acolchonado, (Fig 2).

FAMILIA : CYPERACEAE

3. : Scirpus californicus Britt. «Junco» 
,trígonos, verde oscuro. Hojas reducidas a vainas. Espiguillas ovoides, castaño palido, dispuestas en antelas compuestas, protegidas porunabracteapunzante. Especie variable de origen americano.

Crece en lugares húmedos o fangosos. Propagación por semillas y vegetativamente por rizomas

\section{B. CLASE DYCOTYLEDONAE}

FAMILIA : AIZOACEAE

\section{4. : Sesuvium portulacastrum (L.) "Verdolaga"}

Planta perenne, postrada o ascendente, ramificada. Tallos cilíndricos carnosos, glabros, verdes o cárneo-verdosos en la parte inferior, radicantes en los nudos. Hojas simples, sésiles, suculentas, oblongas, de $1,5-4 \mathrm{~cm}$ de longitud por $0,5-1,5 \mathrm{~cm}$ de ancho, cinéreoverdosas. Flores solitarias axilares. Cáliz 5 , sépalos soldados en su mitad inferior, interiormente rosado purpúreas, enel dorsoverdosos. Corolaausente. Androceo con 10-15 estambres rosado-purpúreos. Gineceo con ovario súpero pentacarpelar. Fruto capsular, dehiscente transversalmente. Semillas numerosas de color negro. Propagación por semillas.

Especie cosmopolita propia de suelos salados. Originaria probablemente del Viejo Mundo.

\section{FAMILIA : BORRAGINACEAE}

5. Heliotropium curassavicum L. "Hierba del alacrán, jaboncillo, heliotropo"

Planta perenne postrada, ramas decumbentes, suculentas de $20-40 \mathrm{~cm}$ de longitud, glabras y glaucas. Hojas alternadas, subsésiles, semisuculentas, lanceoladas, deborde entero, nervaduras po-co marcadas de 1,3-2,3 cm de largo por 2-3,5 mm de ancho. Inflorescencia: Cimas uníparas escorpioideas, axilares y terminales. Flores pequeñas sésiles. Cáliz 5, sépalos glabros. Corolahipocrateriforme, pétalos5, decolor blanco, la corola termina en 5 lóbulos obtusos.Androceo con 5 estambres epicorolinos. Gineceo con estigma subcónico que sale del centro de dos carpelos. Fruto ovoide, rugoso, globoso formado por 4 núculas monospermas. Semilla de tamaño 1,2 - 2 mm. Habita en suelos arenosos halófitos. (Fig. 3).

\section{FAMILIA: VERBENACEAE}

6. Phylanodiflora (L.) Greene "Tiquil-tiquil, turrehembra"

Planta perenne, rastrera o ascendente, de tallos radicantes en los nudos. Hojas simples, opuestas, obovadas, aserradas de 1,2 -5 cm de longitud por 0,5 - 1 $\mathrm{cm}$ de ancho. Flores pequeñas sésiles, reunidas en inflorescencias capituliformes, con un pedúnculo largo.
Cáliz 2 partido, 2-carenado, tubuloso, membranáceo. Corola bilabiada, con pétalos blanco-violáceos, de 2 - 3 $\mathrm{mm}$ de longitud. Androceo con estambres didínamos insertos en el tubo corolino. Ginéceo con ovario súpero, bicarpelar. Fruto esquizocárpico. Crece en suelos arenosos. Deorigenamericano. Propagación por semillas y vegetativamente (Fig. 4).

\section{FAMILIA : SCROPHULARIACEAE}

7. Bacopa monnieri (L.) Pennell « Verdolaga, Hierba de la culebra»

Planta perenne, erguida o rastrera rizomatosa de 20-50 cm de altura. Tallos ramificados, carnosos, cilíndricos, radicantes en los nudos, de color verde o rojizo-verdoso.Hojas simples, opuestas, suculentas, espatuladas o trascordado-cuneiformes de $1.5-3 \mathrm{~cm}$ de largo por 1,2-1,8 cm de ancho. Flores solitarias axilares, hermafroditas, zigomorfas con dos brácteas pequeñas en la base. Cáliz con 5 sépalos desiguales, dos pequeños internos, uno de tamaño regular y dos grandes externos. Corola gamopétala más o menos bilabiada, de lóbulos imbricados, pétalos de color blanco o rosáceo-lila. Androceo con estambres didínamos insertos en el tubo de la corola, alternando con los pétalos. Gineceo, con el ovario súpero bicarpelar y bilocular. Fruto capsular ovoide. Semillas numerosas.

Esta especie se desarrolla vigorosamente donde hay abundancia de agua. Junto a Scirpus californicus, predomina en el bofedal (Fig. 5).

\section{CONCLUSIONES}

Laflora de fanerógamas en las playas de la bahía de lte está representada por siete especies comunes que constituyen la biomasa forrajera para el pastoreo del ganado caprino y ovino:

Distichlis spicata (L.) Greene "Grama Salada", Cynodon dactylon (L.) Pers. "Grama dulce", Scirpus californicus Britt. "Junco", Sesuvium portulacastrum L. "Verdolaga", Heliotropium curassavicum L. «Heliotropo, hierba del alacrán o jaboncillo",

Phyla nodiflora (L.) Greene "Tiquil-tiquil» y Bacopa monnieri (L.) Pennell «Verdolaga».

Dos de estas especies se encuentran en mayor frecuencia, dentrodela vegetación total: Bacopamonnieri (L) Greene "Verdolaga" y Scirpus californicus Britt "Junco". Ellas constituyen un fiel reflejo delas condiciones edáficas reinantes del lugar,en consecuencia, esta vegétación debesertomadacomoun índice dela reacción 
del suelo en el que crecen.

Las especies estudiadas muestran una adaptación a las inundaciones, a niveles medios y elevados de salinidad por la invasión temporal del agua de mar durante las mareas altas. Posiblemente, la producción de biomasa esté relacionada con la tolerancia a niveles elevados de cobre.

\section{BIBLIOGRAFIA}

Braun Blanquet, J. 1964, Sociologia Vegetal. New York - EE.UU

Gola Negri, Cappelletti. 1965, Tratado de Botánica. Ed. Labor S.A.

Zegarra, Rosario.1993, "Estudio biosistemático y posibilidades de control de las malezas halófitas de Tacna y Moquegua». En Nueva Imagen, $\mathrm{N}^{\circ}$ 4, Revista UNJBG, Tacna.

---- 1994, „Vegetación desértica del departamento de Tacna, estudio biosistemático y ecológico". En Nueva Imagen, $N^{\circ} 5$, Revista UNJBG, Tacna.

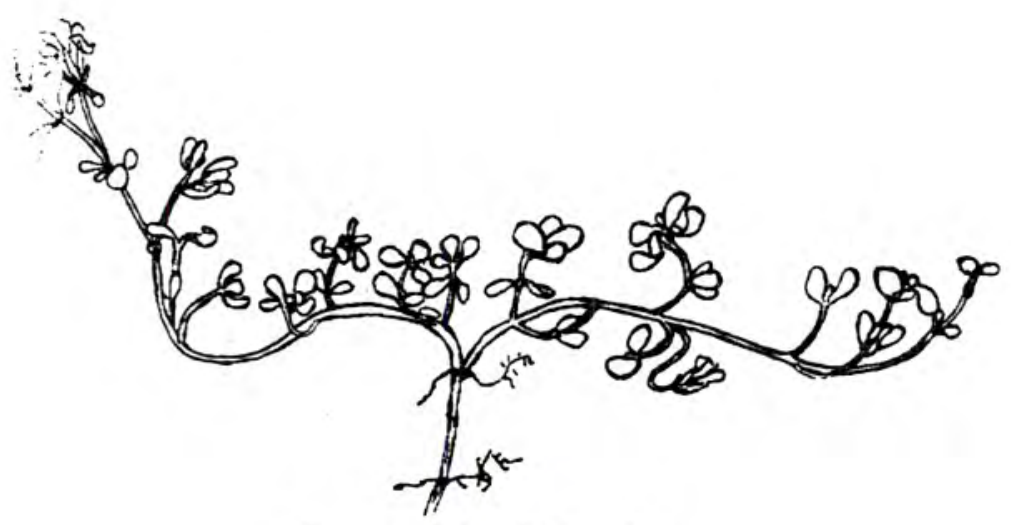

Bacopa momiere (1..)Pennell

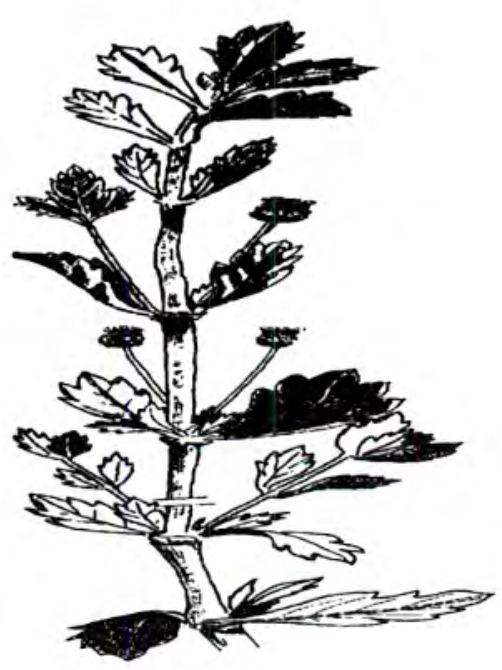

Phila nodiflora var. canescens

(H. B. K. ) Moldenke 

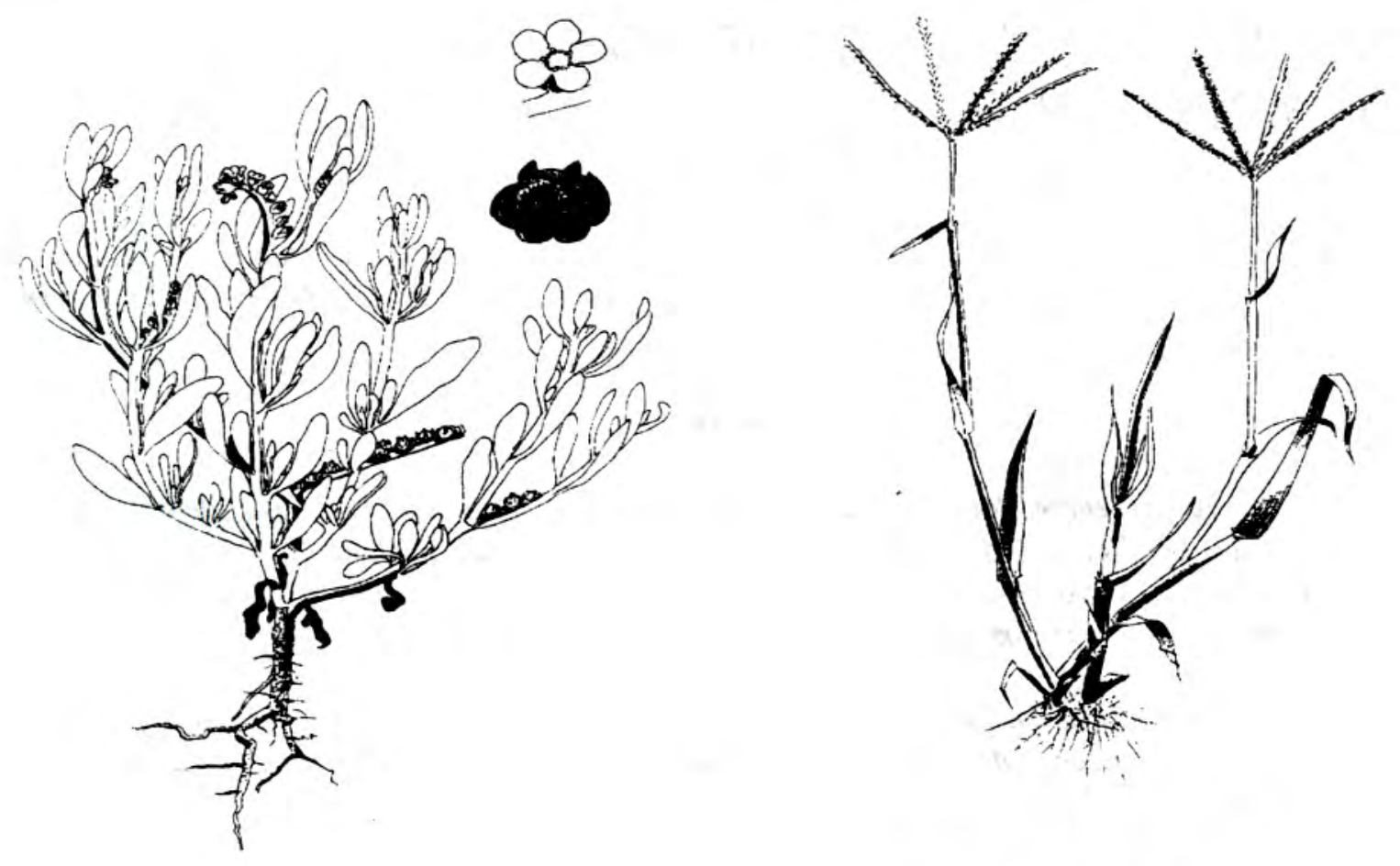

Heliotropium curassavicum L.

Cynodon dactylon (L.) Persoon

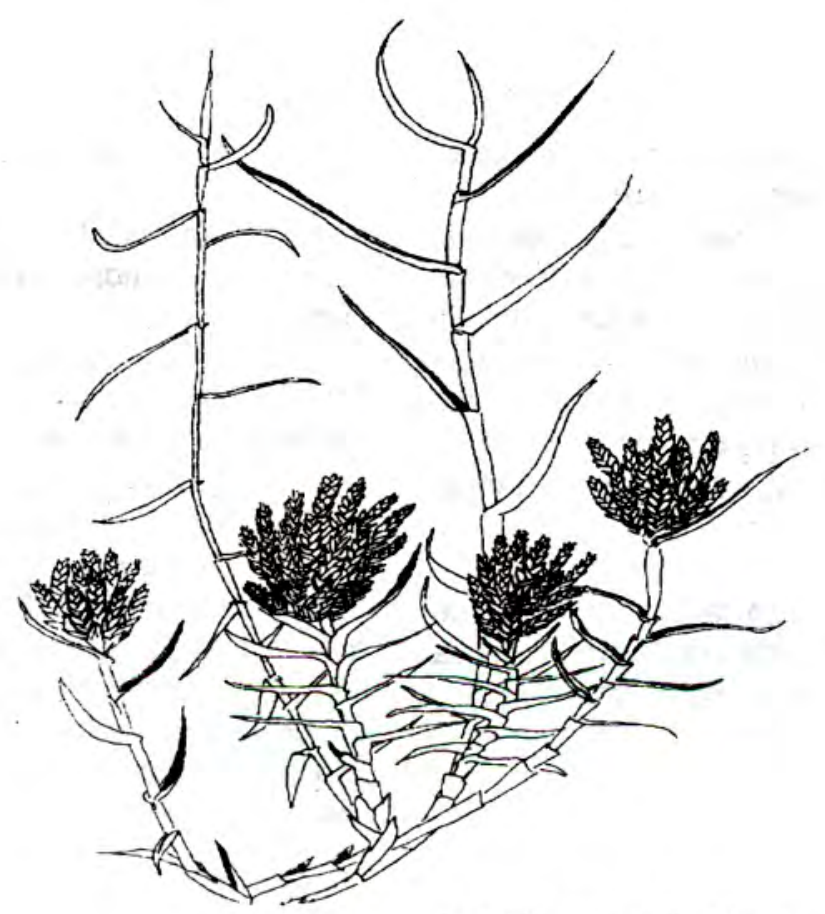

Distichlis spicata (L. ) Grene 